\title{
Effects of Salicylate and Lanthanides on Outer Hair Cell Motility and Associated Gating Charge
}

\author{
Seiji Kakehata and Joseph Santos-Sacchi \\ Sections of Otolaryngology and Neurobiology, Yale University School of Medicine, New Haven, Connecticut 06510
}

Salicylate, one of the most widely used drugs, is known to induce reversible tinnitus and hearing loss. Salicylate interferes with outer hair cells (OHCs), which are believed to underlie normal auditory frequency selectivity and sensitivity. In the present experiments, the effects of salicylate and lanthanides on $\mathrm{OHC}$ motility and nonlinear capacitance were investigated by using isolated guinea-pig OHCs while attempting to avoid inadvertent intracellular pressure change, which itself can affect $\mathrm{OHC}$ motility and capacitance. Either extracellularly or intracelIularly applied salicylate reduced nonlinear peak capacitance $\left(\mathrm{Cm}_{\mathrm{pk}}\right)$ and shifted the voltage at peak capacitance to depolarized levels. Concentration-response curves for reduction in $\mathrm{Cm}_{\mathrm{pk}}$ by salicylate and $\mathrm{GdCl}_{3}$ revealed a half-maximal concentration and Hill coefficient of $1.6 \mathrm{~mm}$ and 1.0 , and $0.6 \mathrm{~mm}$ and 1.2 , respectively. In comparable groups of OHCs, the normal $\mathrm{Cm}_{\mathrm{pk}}$ values of which were near $40 \mathrm{pF}$, average $\mathrm{Cm}_{\mathrm{pk}}$ de-

The outer hair cell $(\mathrm{OHC})$, one of the two receptor cell types in the mammalian organ of Corti, is thought to play a crucial role in hearing by providing a local mechanical feedback into the basilar membrane via its unique voltage-dependent length changes (Brownell et al., 1985; Ashmore, 1987; Santos-Sacchi and Dilger, 1988; Dallos, 1992). This feedback sharpens the passive mechanical vibration of the cochlear partition. Recent studies demonstrate that the $\mathrm{OHC}$ has a nonlinear gating charge movement or, equivalently, a voltage-dependent capacitance that presents characteristics similar to those of $\mathrm{OHC}$ motility, indicating that membrane-bound voltage sensor/motor elements control $\mathrm{OHC}$ length (Ashmore, 1989, 1992; Dallos et al., 1991; Santos-Sacchi, 1991, 1993; Iwasa, 1994).

Salicylate, which is used as an analgesic and anticoagulant, is one of the most widely used drugs. Salicylate is known to produce reversible tinnitus and hearing loss (Myers and Bernstein, 1965; Mongan et al., 1973). Several lines of indirect evidence suggest that salicylate exerts these effects via the OHC (McFadden and Plattsmier, 1984; Long and Tubis, 1988; Puel et al., 1989; Kujawa et al., 1992; Carlyon and Butt, 1993). Indeed, direct studies on the OHC have shown that the nonlinear capacitance and/or motility of the cell can be modified by salicylate (Shehata et al., 1991; Tunstall et al., 1995). Shehata et al. (1991) reported that salicylate reduces $\mathrm{OHC}$ turgor pressure and motility. More recently, Tun-

\footnotetext{
Received March 26, 1996; revised May 16, 1996; accepted May 21, 1996.

This work was supported by National Institutes of Health, National Institute on Deafness and Other Communication Disorders Grant DC00273 to J.S.S. We thank Bill Brownell for critical comments.

Correspondence should be addressed to Dr. Joseph Santos-Sacchi, Sections of Otolaryngology and Neurobiology, BML 244, 333 Cedar Street, New Haven, CT 06510.

Copyright (C) 1996 Society for Neuroscience $0270-6474 / 96 / 164881-09 \$ 05.00 / 0$
}

creased to 28 and $36 \mathrm{pF}$ for intracellularly and extracellularly applied salicylate, respectively. Salicylate reduced, but did not completely block, the voltage-induced length change. Extracellularly, but not intracellularly, applied lanthanide blocked voltage-induced movement and capacitance almost completely. After intracellular trypsin treatment, salicylate reduced voltage-dependent capacitance reversibly, suggesting that salicylate directly acts on the sensor/motor and not via effects on intracellular structures, such as the subsurface cisternae. The results are consistent with the hypothesis that the dissociated, charged form of salicylate directly interacts with the sensor/ motor on the inner aspect of the OHC plasma, whereas lanthanides interact on the outer aspect.

Key words: outer hair cell; salicylate; motility; nonlinear capacitance; gating currents; lanthanides stall et al. (1995) showed that salicylate reduces OHC membrane capacitance and concluded that salicylate is effective in the membrane-permeant uncharged form. Other treatments that are known to affect OHC motility and capacitance include lanthanides and altered turgor pressure, the latter acting via membrane stress (Santos-Sacchi, 1991; Iwasa, 1993; Gale and Ashmore, 1994b; Kakehata and Santos-Sacchi, 1995).

Because whole-cell patch-pipette recording inadvertently can permit changes in OHC turgor pressure (Kakehata and SantosSacchi, 1995), we examined the effect of salicylate and lanthanides on $\mathrm{OHC}$ nonlinear capacitance and voltage-induced mechanical responses while attempting to avoid such interference. The results suggest that each investigated agent seems to work via a different mechanism on the OHC sensor/motor and that the effects of both agents are independent of turgor pressure. Furthermore, the data indicate that the dissociated, charged form of salicylate interacts with the sensor/motor on the inner aspect of the plasma membrane, whereas lanthanides interact with the sensor/motor on the outer aspect.

\section{MATERIALS AND METHODS}

OHCs were freshly isolated from the organ of Corti of the guinea-pig cochlea (Kakehata et al., 1993) and were whole-cell voltage-clamped by an Axon 200 amplifier with patch pipettes having initial resistances of 2-3 $\mathrm{M} \Omega$ or $\sim 10 \mathrm{M} \Omega$, corresponding to tip sizes of $1-2 \mu \mathrm{m}$ or $\sim 0.5 \mu \mathrm{m}$, respectively (Hamill et al., 1981). Residual series resistance $\left(R_{\mathrm{s}}\right.$; after electronic compensation) ranged from 3 to $7 \mathrm{M} \Omega$ and from 20 to $30 \mathrm{M} \Omega$, respectively. Ionic blocking solutions were used to remove voltagedependent ionic conductances so that capacitive currents could be analyzed in isolation (Santos-Sacchi, 1991; Huang and Santos-Sacchi, 1993). The patch-pipette solution contained (in $\mathrm{mM}$ ): $140 \mathrm{CsCl}, 2 \mathrm{MgCl}_{2}, 10$ EGTA, and 10 HEPES, pH 7.2; osmolarity was adjusted with dextrose to 300 mOsm. The external solution contained (in mM): $100 \mathrm{NaCl}, 20$ TEA, 
$20 \mathrm{CsCl}, 2 \mathrm{CoCl}_{2}, 1.52 \mathrm{MgCl}_{2}, 10 \mathrm{HEPES}$, and 5 dextrose, $\mathrm{pH} 7.2$, at 300 mOsm. In some experiments, extracellular $\mathrm{CaCl}_{2}(2 \mathrm{mM})$ was included, without any effect. Drugs were applied by using the Y-tube method (Murase et al., 1990) during simultaneous whole-chamber perfusion. Experiments were performed at room temperature.

A tracking procedure was used to monitor continuously the voltage at peak nonlinear capacitance $\left(V_{\mathrm{pkCm}}\right)$ after obtaining whole-cell configuration (Kakehata and Santos-Sacchi, 1995). The program Clampex (Axon Instruments, Foster City, CA) was modified to perform the $V_{\mathrm{pkCm}}$ tracking procedure on-line, and membrane potential was corrected for the effects of residual series resistance. Peak capacitance $\left(\mathrm{Cm}_{\mathrm{pk}}\right)$ values also were monitored during the tracking procedure by using transient analysis of capacitive currents induced by a $-10 \mathrm{mV}$ step.

Detailed, corroborative evaluation of membrane capacitance was made at different potentials by transient analysis of currents induced by a voltage stair-step stimulus, and the capacitance function was fit to the first derivative of a two-state Boltzmann function relating nonlinear charge to membrane voltage (d $Q / \mathrm{d} V$; Santos-Sacchi, 1991; Huang and SantosSacchi, 1993):

$$
C_{\mathrm{m}}=Q_{\max } \frac{z e}{k T} \frac{b}{(1+b)^{2}}+C_{\text {lin }},
$$

in which

$$
b=\exp \left(\frac{-z e\left(V-V_{\mathrm{pkCm}}\right)}{k T}\right)
$$

$Q_{\max }$ is the maximum nonlinear charge moved, $V_{\mathrm{pkCm}}$ is voltage at peak capacitance or, equivalently, at half-maximal nonlinear charge transfer, $V_{\mathrm{m}}$ is membrane potential, $z$ is valence, $C_{\text {lin }}$ is linear membrane capacitance, $e$ is electron charge, $k$ is Boltzmann's constant, and $T$ is absolute temperature. Pipette pressure was modified with a syringe connected to the Teflon tubing attached to the patch-pipette holder. Pressure was monitored via a T-connector to a pressure monitor (World Precision Instruments, Sarasota, FL). An in-house pipette pressure clamp was used to maintain constant pipette pressure when required. This device provided positive or negative pressure into the pipette via a motor-driven, gas-tight syringe by using feedback from the pressure monitor.

Previously, we have found that when recording with large-tipped patch pipettes (1.5-3 M $\Omega, 1.5 \mu \mathrm{m}$ tip) containing iso-osmolar solutions, $V_{\mathrm{pkCm}}$ shifts to hyperpolarized levels over the course of $10 \mathrm{~min}$ after patch membrane rupture (Kakehata and Santos-Sacchi, 1995). This occurs because of a decrease in $\mathrm{OHC}$ intracellular pressure. In the present set of experiments, three conditions were used to dismiss potential effects of uncontrolled, recording-induced intracellular pressure change during evaluation of salicylate and lanthanides on OHC capacitance and motility. First, the use of small-tipped pipettes provides for stable intracellular pressures, because no negative shifts of $V_{\mathrm{pkCm}}$ are observed over periods of $30 \mathrm{~min}$ or longer. Under this condition, the potential effects of exogenous agents on intracellular pressure are unhampered. Second, with large-tipped pipettes, maintenance of constant pipette pressure provides for stable intracellular pressures, because $V_{\mathrm{pkCm}}$ can be maintained constant. Third, with large-tipped pipettes after intracellular pressure dissipation $(\sim 10 \mathrm{~min})$, intracellular pressure is stable, because $V_{\mathrm{pkCm}}$ remains constant. The drugs were evaluated under each condition.

All experiments were video taped with a Matrox (Montreal, Canada) video overlay board that combines EGA and video. Measures of voltageinduced $(20 \mathrm{mV}$ increments) mechanical responses were made from the video monitor with a differential optoresistor technique (Santos-Sacchi, 1989, 1991). Mechanical data were fit to a two-state Boltzmann function to determine the voltage at maximum sensitivity $\left(V_{\delta \text { Lmax }}\right)$.

Dose-response data were averaged and are given as mean \pm SE. A continuous theoretical curve was drawn according to a modified Michaelis-Menten equation with the use of a least-squares fitting routine after normalization of the response,

$$
\Delta C=C_{\max }\left(C^{n} / C^{n}+K_{D}^{n}\right),
$$

in which $\Delta C$ is the observed reduction of capacitance, $C$ is the drug concentration, $K_{\mathrm{D}}$ is the dissociation constant, and $n$ is the Hill coefficient. All data analysis was performed with the software package MATLAB (Mathworks, Natick, MA).
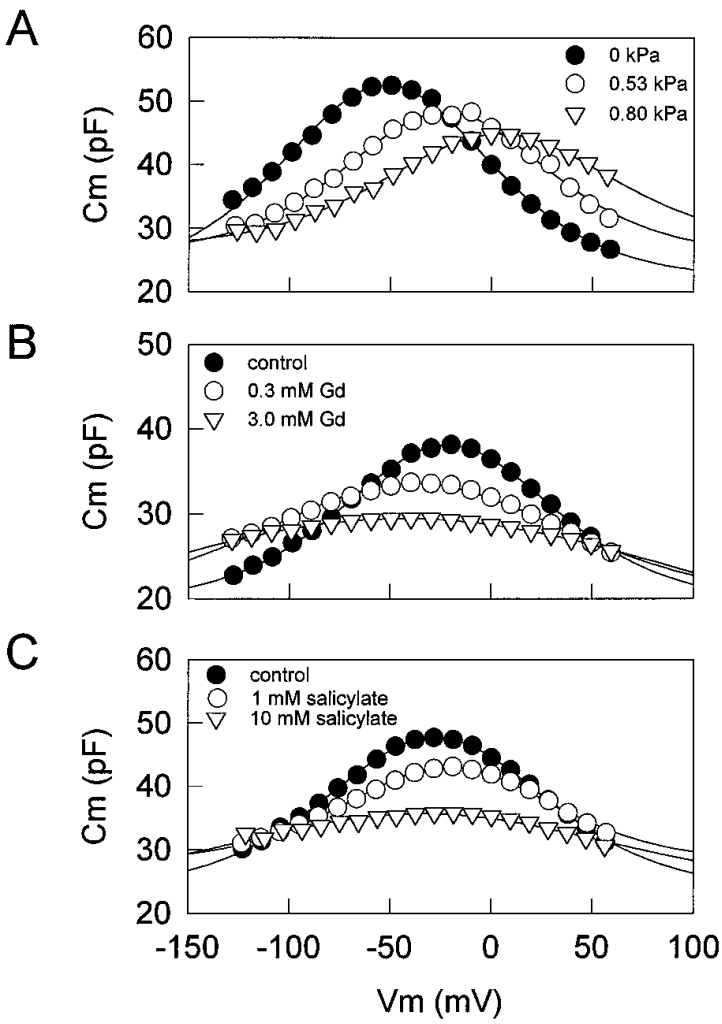

Figure 1. Effects of intracellular pressure $(A)$, lanthanides $(B)$, and salicylate $(C)$ on $C m$. Voltage-dependent capacitance was obtained by the voltage stair-step technique. $A$, After $V_{\mathrm{pkCm}}$ stabilized after intracellular pressure dissipation $(\sim 10 \mathrm{~min})$, an increasing intracellular pressure caused a positive shift in the $V_{\mathrm{pkCm}}$ with decreasing peak capacitance $\left(C m_{\mathrm{pk}}\right) \cdot R_{\mathrm{s}}$ (series resistance), $1.9 \mathrm{M} \Omega$ (pipette tip, $\left.\sim 1.5 \mu \mathrm{m}\right) ; R_{\mathrm{m}}$ (membrane resistance), $139 \mathrm{M} \Omega$. The initial cell length was $75 \mu \mathrm{m}$; the cell length was reduced to $73 \%$ when intracellular pressure was increased to $0.8 \mathrm{kPa}$. $B$, In another cell, after $V_{\mathrm{pkCm}}$ stabilized, $\mathrm{GdCl}_{3}$ was applied extracellularly by a Y-tube delivery system. $\mathrm{GdCl}_{3}$ caused a negative shift in $V_{\mathrm{pkCm}}$ with decreasing $C m_{\mathrm{pk}} . R_{\mathrm{s}}, 2.8 \mathrm{M} \Omega$ (pipette tip, $\sim 1 \mu \mathrm{m}$ ); $R_{\mathrm{m}}, 220$ $\mathrm{M} \Omega$. The initial cell length was $50 \mu \mathrm{m}$; the cell length elongated to $107 \%$. $C$, In another cell, with the use of a small-tipped pipette to maintain initial intracellular turgor pressure, extracellularly applied salicylate caused a positive shift in $V_{\mathrm{pkCm}}$ with decreasing $C m_{\mathrm{pk}} . R_{\mathrm{s}}, 27.2 \mathrm{M} \Omega ; R_{\mathrm{m}}, 350 \mathrm{M} \Omega$. The initial cell length was $65 \mu \mathrm{m}$; the cell length was reduced to $78 \%$. All treatments were done after $V_{\mathrm{pkCm}}$ stabilized.

\section{RESULTS}

\section{Effects of salicylate, lanthanides, and pressure on OHC nonlinear capacitance}

Figures 1 and 2 illustrate the effects of intracellular pressure changes and extracellularly applied salicylate and lanthanides on $\mathrm{OHC}$ nonlinear capacitance. Positive changes in intracellular pressure consistently and reversibly shifted $V_{\mathrm{pkCm}}$ to depolarized levels and reduced $\mathrm{Cm}_{\mathrm{pk}}$ (Figs. $1 A, 2 A$ ). Lanthanides such as $\mathrm{GdCl}_{3}, \mathrm{LuCl}_{3}$, and $\mathrm{CeCl}_{3}$ consistently, but not always reversibly, shifted $V_{\mathrm{pkCm}}$ to hyperpolarized levels and reduced $\mathrm{Cm}_{\mathrm{pk}}$ (Figs. $1 B, 2 B)$. However, whereas salicylate consistently and reversibly shifted $V_{\mathrm{pkCm}}$ and reduced $C m_{\mathrm{pk}}$, the direction of the shift could be to either depolarized or hyperpolarized levels (Figs. $1 C, 2 C, D$ ). About two-thirds of the cells tested exhibited a shift in the depolarized direction (Fig. 2C). Residual ionic conductance (leakage) remained unaffected by salicylate or intracellular pressure changes, but lanthanides suppressed it. These results suggest that lanthanides and salicylate do not exert their effects simply via a 

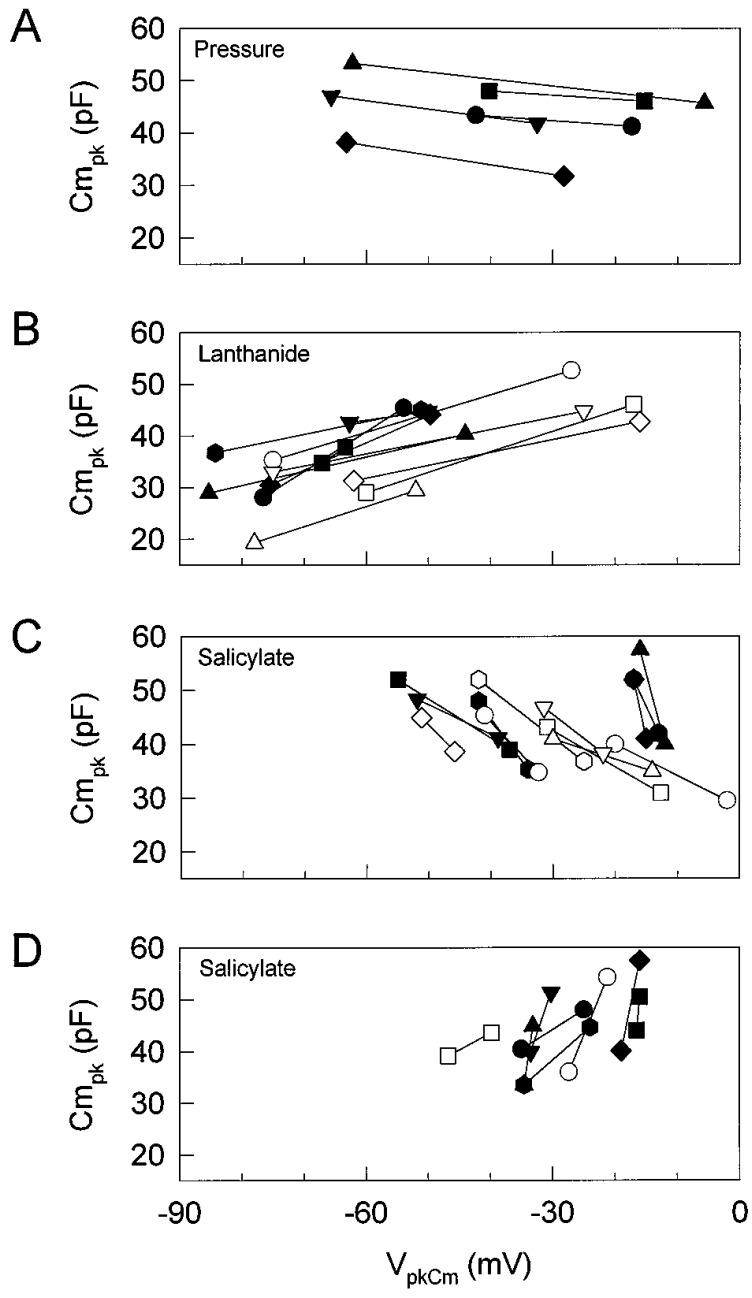

Figure 2. Effects of intracellular pressure $(A)$, lanthanides $(B)$, and salicylate $(C, D)$ on the relationship between $V_{\mathrm{pkCm}}$ and $C m_{\mathrm{pk}}$. Each point shows the relationship between $V_{\mathrm{pkCm}}$ and $C m_{\mathrm{pk}}$. Increasing pressure, extracellularly applied lanthanides, or salicylate reduces $C m_{\mathrm{pk}} \cdot A, C m_{\mathrm{pk}}$ and $V_{\mathrm{pkCm}}$ under two pressure conditions, $-0.41 \pm 0.26$ (mean $\pm \mathrm{SE}$ ) and $0.64 \pm 0.23 \mathrm{kPa}$. Increasing pressure caused a positive shift in $V_{\mathrm{pkCm}} . B$, $C m_{\mathrm{pk}}$ and $V_{\mathrm{pkCm}}$ before and during application of lanthanides $(3$ or $10 \mathrm{~mm}$ $\left.\mathrm{GdCl}_{3}, n=7 ; 1 \mathrm{mM} \mathrm{LuCl}_{3}, n=3 ; 1 \mathrm{mM} \mathrm{CeCl}_{3}, n=1\right)$. Extracellularly applied lanthanides caused a negative shift in $V_{\mathrm{pkCm}}$ with decreasing $C m_{\mathrm{pk}}$ in all cells tested $(n=11)$. Reversibility was dependent on concentration. $C, D, C m_{\mathrm{pk}}$ and $V_{\mathrm{pkCm}}$ before and during application of $10 \mathrm{~mm}$ salicylate. Extracellularly applied salicylate reduced $\mathrm{Cm}_{\mathrm{pk}}$, although the direction of the shift in $V_{\mathrm{pkCm}}$ was variable. The data are plotted in separate graphs for clarity. Of 21 cells tested, 13 showed a positive shift in $V_{\mathrm{pkCm}}(C)$, and 8 cells showed a negative shift $(D)$. Each symbol indicates a different cell. All treatments were done after $V_{\mathrm{pkCm}}$ stabilized.

mechanism similar to that of turgor pressure change, which is believed to act via alterations in membrane stress (Iwasa, 1994; Kakehata and Santos-Sacchi, 1995).

The response time course of extracellularly applied salicylate was examined by using a tracking procedure to follow changes in $V_{\mathrm{pkCm}}$ and $\mathrm{Cm}_{\mathrm{pk}}$ (Kakehata and Santos-Sacchi, 1995). One millimolar salicylate reversibly reduced $\mathrm{Cm}_{\mathrm{pk}}$ and shifted $V_{\mathrm{pkCm}}$ to depolarized levels (Fig. $3 A$ ). These effects reached steady state in $\sim 60 \mathrm{sec}$ in this cell. An increase in the salicylate concentration accelerated the response (Fig. $3 B$ ). The reduction of $\mathrm{Cm}_{\mathrm{pk}}$ was well fit with a single exponential. Tau of salicylate-induced reduction in $C m_{\mathrm{pk}}$ was $19.2 \pm 3.7 \mathrm{sec}($ mean $\pm \mathrm{SE} ; n=5)$ and $11.4 \pm$
A

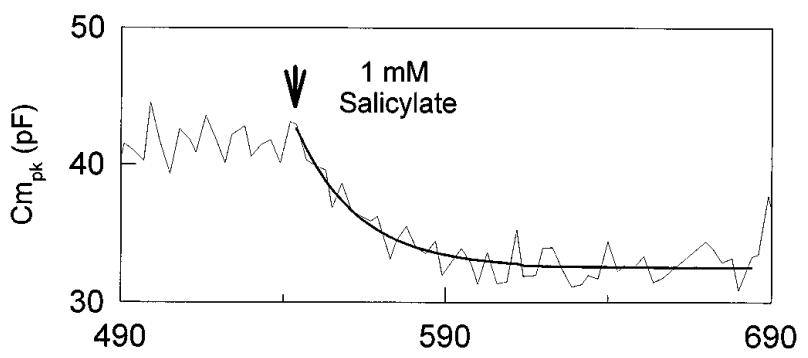

B

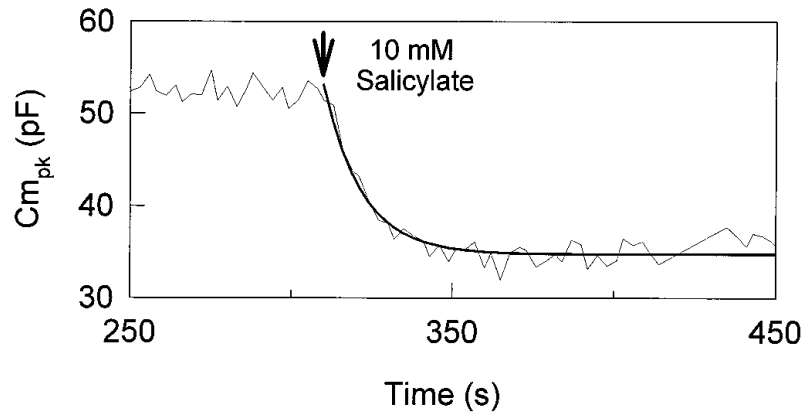

Figure 3. Effects of extracellularly applied salicylate on OHC capacitance. The effective time course of extracellularly applied salicylate was examined by using a tracking procedure. A small-tipped pipette was used to permit any turgor pressure change that salicylate may cause. Salicylate was applied after $V_{\mathrm{pkCm}}$ and $C m_{\mathrm{pk}}$ reached steady state. $A$, Effects of $1 \mathrm{~mm}$ salicylate. Peak capacitance is shown as a function of time. The reduction of $C m_{\mathrm{pk}}$ is well fit by using a single exponential curve fit. Tau is $19 \mathrm{sec} . R_{\mathrm{s}}$, $27.1 \mathrm{M} \Omega ; R_{\mathrm{m}}, 255 \mathrm{M} \Omega$. B, Effects of $10 \mathrm{~mm}$ salicylate in a different cell. Tau is 12 sec. $R_{\mathrm{s}}, 26.6 \mathrm{M} \Omega ; R_{\mathrm{m}}, 292 \mathrm{M} \Omega$.

$2.4 \mathrm{sec}(n=8)$ for 1 and $10 \mathrm{~mm}$ salicylate, respectively. With the use of fitted steady-state values, the average reduction of $\mathrm{Cm}_{\mathrm{pk}}$ and average shift of $V_{\mathrm{pkCm}}($ mean $\pm \mathrm{SE}$ ) were $6.82 \pm 1.48 \mathrm{pF}$ and $4.6 \pm 2.2 \mathrm{mV}(1 \mathrm{~mm} ; n=5)$, and $10.63 \pm 1.51 \mathrm{pF}$ and $16.7 \pm 2.2$ $\mathrm{mV}(10 \mathrm{~mm} ; n=7)$. Nonlinear capacitance was evaluated more fully by using stair-step stimuli applied at least $120 \mathrm{sec}$ after treatment. With this technique, average $C m_{\mathrm{pk}}$ was $46.86 \pm 1.25$ $(n=11)$ and $36.75 \pm 0.92 \mathrm{pF}$ before and during application of 10 mM salicylate, respectively. The average reduction of $\mathrm{Cm}_{\mathrm{pk}}$ was $10.11 \pm 1.26 \mathrm{pF}$, which is comparable to the value of $10.63 \pm 1.51$ $\mathrm{pF}$ obtained by the tracking technique.

\section{Concentration-response curves for salicylate and gadolinium}

Concentration-response curves for reduction in $\mathrm{Cm}_{\mathrm{pk}}$ by salicylate were obtained with the $V_{\mathrm{pkCm}}$ tracking technique. Salicylate was applied by Y-tube in increasing concentrations, without intermittent washing, until a steady-state response was achieved. Pipette pressure was kept slightly positive (up to approximately $+0.07 \mathrm{kPa}$ ), to prevent turgor dissipation. Figure $4 A$ shows a representative example. The effects of salicylate were just detectable at a concentration of $\sim 300 \mu \mathrm{M}$. The reduction increased sigmoidally as the salicylate concentration increased to $10 \mathrm{mM}$, above which the response was saturated. The half-maximal concentration $\left(K_{1 / 2}\right)$ and the Hill coefficient $(n)$ were $1.6 \mathrm{~mm}$ and 1.0, respectively. $V_{\mathrm{pkCm}}$ shifted to depolarized levels at a concentration of $>1 \mathrm{~mm}$.

Concentration-response curves for $\mathrm{GdCl}_{3}$ were obtained in a similar manner. Pipette pressure was kept positive (up to approximately $+0.14 \mathrm{kPa}$ ) to prevent turgor dissipation. Compared with salicylate, longer perfusion times were required to reach steady- 

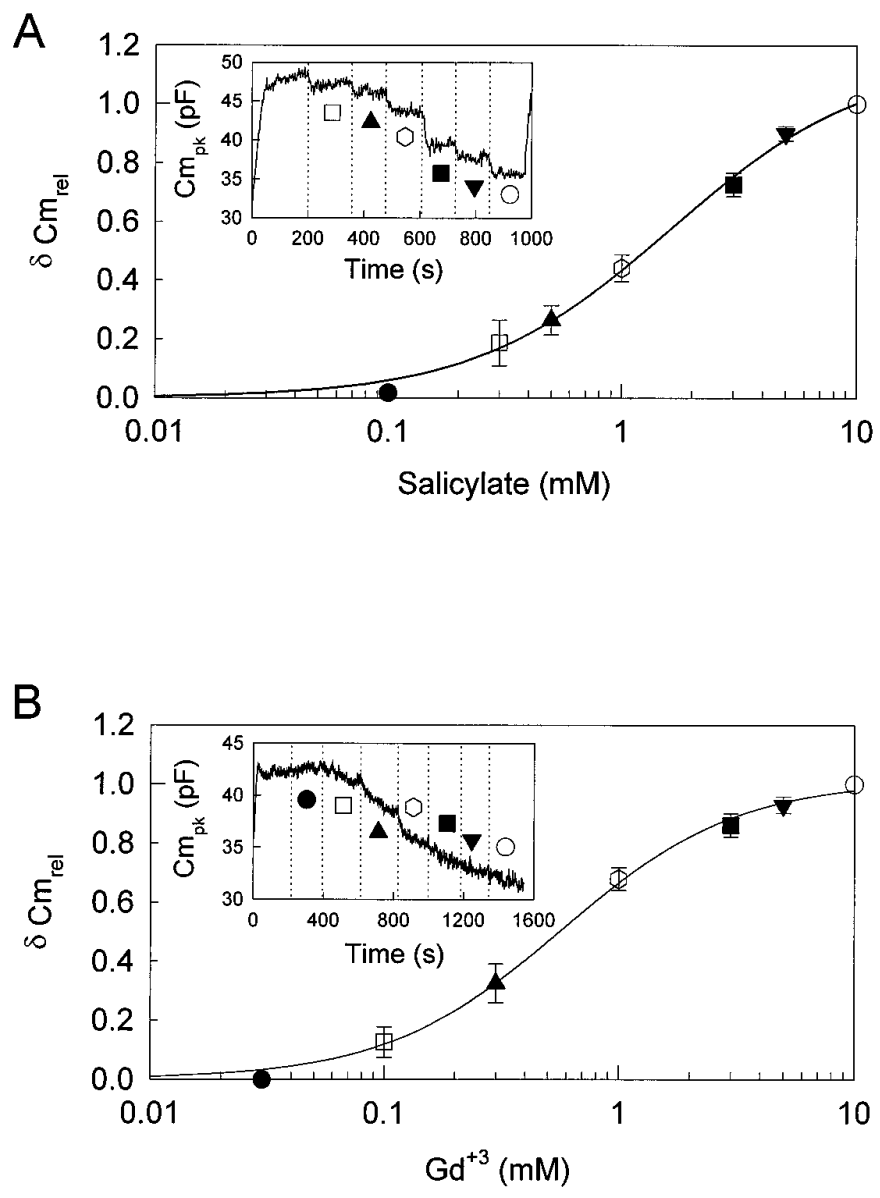

Figure 4. Concentration-response curve for reduction in $\mathrm{Cm}_{\mathrm{pk}}$ by salicylate and $\mathrm{GdCl}_{3}$. A, The concentration-response curve for salicylate. The inset shows the effect on the $C m_{\mathrm{pk}}$ by various concentrations of salicylate in a representative example. $R_{\mathrm{s}}, 5.5 \mathrm{M} \Omega ; R_{\mathrm{m}}, 450 \mathrm{M} \Omega$. Pipette pressure was kept at $0 \mathrm{kPa}$. Reductions of $C m_{\mathrm{pk}}$ induced by various concentrations were normalized to the reduction induced by $10 \mathrm{~mm}$ salicylate. Each point is the mean $\pm \mathrm{SE}$ of five cells. $B$, The concentration-response curve for $\mathrm{GdCl}_{3}$. The inset shows the effect on the $C m_{\mathrm{pk}}$ by various concentrations of $\mathrm{GdCl}_{3}$ in a representative example. $R_{\mathrm{s}}, 6.5 \mathrm{M} \Omega ; R_{\mathrm{m}}, 400 \mathrm{M} \Omega$. Pipette pressure was kept at $0.11 \mathrm{kPa}$. Reductions of $C m_{\mathrm{pk}}$ induced by various concentrations were normalized to the reduction induced by $10 \mathrm{~mm}$ $\mathrm{GdCl}_{3}$. Each point is the mean $\pm \mathrm{SE}$ of five cells determined at the end of each perfusion.

state levels (Fig. 4B). The effects of $\mathrm{GdCl}_{3}$ were detectable at a concentration of $100 \mu \mathrm{M}$. $\mathrm{GdCl}_{3}$ reduced $\mathrm{Cm}_{\mathrm{pk}}$ in a concentrationdependent manner, and at $10 \mathrm{~mm}$ a near-maximal response was obtained. $K_{1 / 2}$ and $n$ were $0.6 \mathrm{~mm}$ and 1.2 , respectively. $V_{\mathrm{pkCm}}$ shifted to hyperpolarized levels and reached very negative potentials of $-67.4 \pm 3.9 \mathrm{mV}(n=5)$. Two of the treated cells collapsed during data collection.

\section{Effects of intracellularly applied salicylate}

Recent evidence indicates that salicylate is highly permeable through the OHC membrane (Tunstall et al., 1995; Zhi et al., 1996). However, the precise site in which salicylate acts on the OHC motility voltage sensor remains unknown. To investigate possible sites of salicylate effects, we applied salicylate intracellularly through patch pipettes and compared results with those obtained by extracellular application. Large-tipped pipettes were used, with pipette pressure clamped near zero. Tracking of $\mathrm{Cm}_{\mathrm{pk}}$

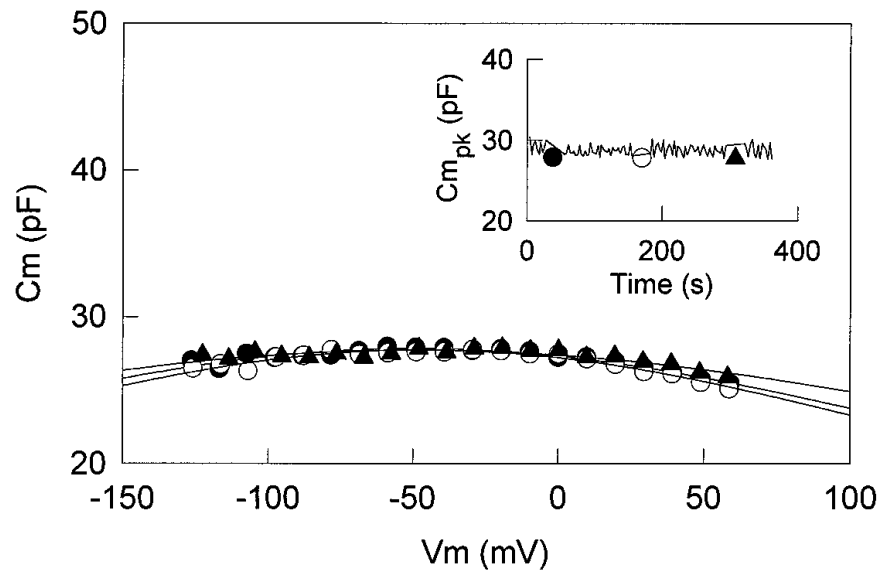

Figure 5. Effects of intracellularly applied salicylate on OHC capacitance. The $\mathrm{OHC}$ was dialyzed with a pipette solution containing $10 \mathrm{~mm}$ salicylate. The inset shows peak capacitance as a function of time, measured with the tracking procedure (solid line) or stair-step protocol (symbols at 30,160, and $300 \mathrm{sec}$ ). $R_{\mathrm{s}}, 6.01 \mathrm{M} \Omega ; R_{\mathrm{m}}, 270 \mathrm{M} \Omega$. Capacitance drops to low levels immediately after obtaining whole-cell configuration. This figure is representative of 20 cells tested.

and $V_{\mathrm{pkCm}}$ was started immediately after whole-cell configuration was obtained. In addition, stair-step stimuli in a wide voltage range $(-150$ to $+150 \mathrm{mV})$ were applied periodically. Figure 5 shows the immediate effect of intracellularly applied salicylate on voltage-dependent capacitance. In OHCs dialyzed with $5 \mathrm{~mm}$ salicylate, stair-step analysis revealed that reduction of $\mathrm{Cm}_{\mathrm{pk}}$ and the shift of $V_{\mathrm{pkCm}}$ were time-dependent (data not shown). In two cells, the exponential time constant of $\mathrm{Cm}_{\mathrm{pk}}$ reduction was 11.25 and $6.89 \mathrm{sec}$. With $10 \mathrm{~mm}$ salicylate, $C m_{\mathrm{pk}}$ was reduced to a steady level of $<30 \mathrm{pF}$ within, at most, $5 \mathrm{sec}$ after whole-cell configuration was obtained (Fig. 5).

Because the effects of intracellularly applied salicylate are so rapid, it is impossible to obtain the initial normal capacitance value of the cell for comparison. Instead, we compared groups of intracellularly untreated and treated $(10 \mathrm{~mm})$ cells, the average cell length of which was $56.7 \pm 3.1(n=11)$ and $58.5 \pm 3.4 \mu \mathrm{m}$ $(n=11)$, respectively. OHC length correlates well with the membrane capacitance of the cell; thus, valid comparisons can be made between these groups. Average $C m_{\mathrm{pk}}$ was $46.87 \pm 1.25$ and $28.20 \pm 0.67 \mathrm{pF}$ in untreated and treated groups, respectively. In those control OHCs subsequently treated with extracellular 10 mM salicylate, the average $C m_{\mathrm{pk}}$ dropped to $36.75 \pm 0.92 \mathrm{pF}$. This value differs significantly from the value of $28.20 \pm 0.67 \mathrm{pF}$ in the OHCs dialyzed with $10 \mathrm{~mm}$ salicylate (Student's $t$ test $<0.001$ ). These results indicate that salicylate works more effectively when applied intracellularly.

Voltage-induced $\mathrm{OHC}$ movement and voltage-dependent capacitance share many characteristics (Santos-Sacchi, 1991; Ashmore, 1992). OHC voltage-dependent movement as well as voltage-dependent capacitance were reduced in a concentrationdependent manner by intracellular salicylate treatment (Fig. 6). In the absence of salicylate, voltage-induced length changes saturate at positive voltages. The voltage in which saturation initiates depends on OHC turgor pressure, because $V_{\delta \text { Lmax }}$ shifts with turgor pressure (Kakehata and Santos-Sacchi, 1995). The maximum mechanical gain of the $\mathrm{OHC}$, however, can remain fairly constant. Thus, to avoid the possible effect of turgor pressure on measures of $\mathrm{OHC}$ movement, we compared maximum mechanical 

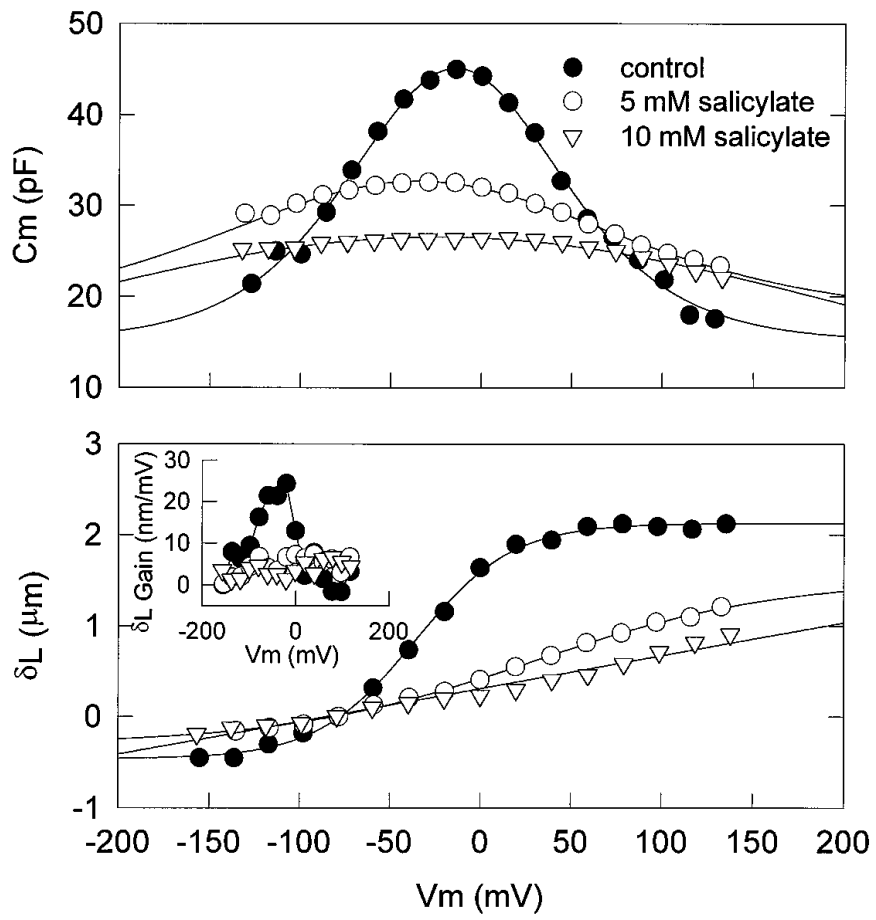

Figure 6. Effects of intracellularly applied salicylate on OHC capacitance and movement. Voltage-dependent capacitance and voltage-induced length change were measured 3-4 min after whole-cell configuration in three different cells. As the concentration of salicylate increased, voltagedependent capacitance and nonlinearity of voltage-induced length change were reduced correspondingly. Length changes were induced by $20 \mathrm{mV}$ steps from -150 to $+150 \mathrm{mV}$ at a $V_{\text {hold }}$ of $-80 \mathrm{mV}$. $R_{\mathrm{s}}, 3.38 \mathrm{M} \Omega$ and $R_{\mathrm{m}}$, $66.5 \mathrm{M} \Omega$ (closed circles); $R_{\mathrm{s}}, 3.68 \mathrm{M} \Omega$ and $R_{\mathrm{m}}, 34.7 \mathrm{M} \Omega$ (open circles); $R_{\mathrm{s}}$, $6.57 \mathrm{M} \Omega$ and $R_{\mathrm{m}}, 240 \mathrm{M} \Omega$ (open triangles). Fits (solid lines) for capacitance indicate $V_{\mathrm{pkCm}}, Q_{\mathrm{max}}$, and $z$ of $-14.3 \mathrm{mV}, 4.74 \mathrm{pC}$, and 0.650 (open circles); $-38.2 \mathrm{mV}, 5.09 \mathrm{pC}$, and 0.317 (closed circles); $-28.7 \mathrm{mV}, 36.54 \mathrm{pC}$, and 0.111 (open triangles). Fits for the mechanical data indicate $V_{\text {hold }}$ and $z$ of $-36.4 \mathrm{mV}$ and 0.955 (closed circles), $2.89 \mathrm{mV}$ and 0.376 (open circles), and $6.43 \mathrm{mV}$ and 0.039 (open triangles). The inset shows the first derivative of the mechanical responses, indicating the gain of the mechanical response with different concentrations of salicylate. See text for details.

gain of OHCs in the absence and presence of intracellular salicylate. The average gain was $19.53 \pm 1.98 \mathrm{~nm} / \mathrm{mV}(n=3)$ in the absence of salicylate, which is in line with previous measures (Ashmore,1987; Santos-Sacchi and Dilger, 1988). In the presence of $10 \mathrm{~mm}$ salicylate, voltage-induced length change did not saturate, and the movement function appeared linear within the voltage range of -150 to $150 \mathrm{mV}$. The average cell-length change obtained by a voltage step from a holding potential of -80 to 150 $\mathrm{mV}$ was $1.03 \pm 0.06 \mu \mathrm{m}(n=7)$. The average maximum mechanical gain was $5.17 \pm 0.43 \mathrm{~nm} / \mathrm{mV}(n=9)$, which is about onefourth of the average gain in the absence of salicylate.

\section{Comparison of effects between salicylate and lanthanide on $\mathrm{OHC}$ capacitance and movement}

The effect of salicylate on $\mathrm{OHC}$ nonlinear capacitance is similar to that of lanthanides, which are known to block voltage-dependent OHC movement and capacitance (Santos-Sacchi, 1991; Kakehata and Santos-Sacchi, 1995). However, significant differences exist between the effects of the two drugs and are revealed via dualtreatment experiments. In OHCs dialyzed with $10 \mathrm{~mm}$ salicylate, simultaneous measures of capacitance and voltage-dependent movements were made before and during extracellular applica-
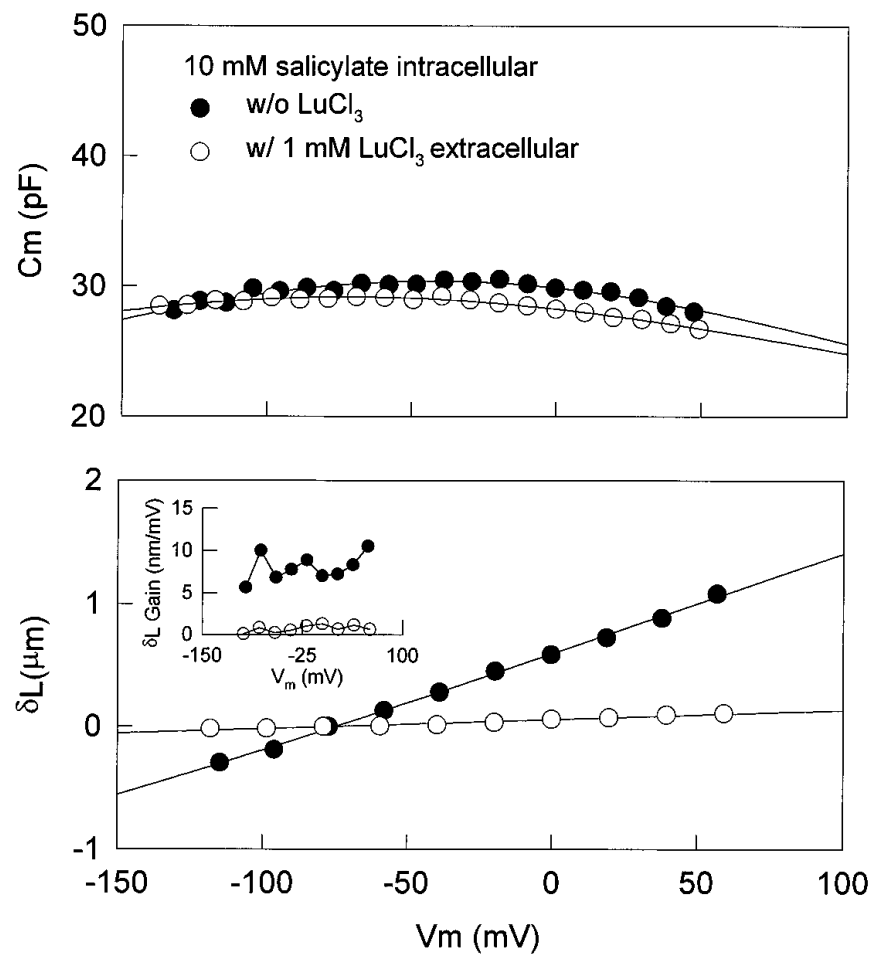

Figure 7. Comparison of effects between salicylate and lanthanide on OHC capacitance and movement. Voltage-dependent capacitance and voltage-induced length change were measured before and during extracellularly applied $\mathrm{LuCl}_{3}(1 \mathrm{mM})$ in an $\mathrm{OHC}$ with intracellularly applied salicylate $(10 \mathrm{mM})$. Length changes were induced by $20 \mathrm{mV}$ steps from -20 to $+60 \mathrm{mV}$ at a $V_{\text {hold }}$ of $-80 \mathrm{mV} . R_{\mathrm{s}}, 4.75 \mathrm{M} \Omega$ and $R_{\mathrm{m}}, 89.2 \mathrm{M} \Omega$ (closed circles); $R_{\mathrm{s}}, 4.39 \mathrm{M} \Omega$ and $R_{\mathrm{m}}, 261 \mathrm{M} \Omega$ (open circles). Fits (solid lines) for capacitance indicate $V_{\mathrm{pkCm}}, Q_{\mathrm{max}}$, and $z$ of $-42.3 \mathrm{mV}, 9.152 \mathrm{pC}$, and 0.205 (open circles); $-71.3 \mathrm{mV}, 7.35 \mathrm{pC}$, and 0.191 (closed circles). Fitting such depressed capacitance functions may not be reliable because of the limited voltage range that can be applied. The mechanical data could not be fit reliably with a two-state Boltzmann. Note that lanthanides, although changing the capacitance function minimally, effectively block mechanical responses. The inset shows mechanical gain of the cell under each condition.

tion of $1 \mathrm{~mm} \mathrm{LuCl}_{3}$. An example is shown in Figure 7. At $4 \mathrm{~min}$ after whole-cell configuration, $C m_{\mathrm{pk}}$ was $30.4 \mathrm{pF}$, and $z$ was 0.205 . Extracellularly applied $\mathrm{LuCl}_{3}$ further reduced $\mathrm{Cm}_{\mathrm{pk}}$ and $z$ to a small extent, namely, $29.2 \mathrm{pF}$ and 0.191 , respectively. On the other hand, the effect elicited by $\mathrm{LuCl}_{3}$ on the cell movement was significant. Voltage-induced movement was blocked almost completely; i.e., maximum mechanical gain was reduced from 8.04 to $0.70 \mathrm{~nm} / \mathrm{mV}$.

The effect of intracellularly applied lanthanide also was examined. Because EDTA-like calcium buffers are powerful lanthanide chelators, $\mathrm{GdCl}_{3}(5 \mathrm{~mm})$ was added to patch pipettes that did not include EGTA. Intracellularly applied $\mathrm{GdCl}_{3}$ neither abolished the voltage-induced movement nor reduced nonlinear capacitance in all cells tested (data not shown; $n=4$ ). This result suggests that lanthanides work exclusively from the extracellular side of the OHC membrane.

\section{Effects of salicylate on the limiting value of $\boldsymbol{V}_{\mathrm{pkCm}}$}

As $\mathrm{OHC}$ intracellular pressure is reduced, $V_{\mathrm{pkCm}}$ shifts in the negative direction until it reaches a limiting value that occurs when the cell collapses (Kakehata and Santos-Sacchi, 1995). Figure 8 illustrates the effects of salicylate on this limiting value. 
A
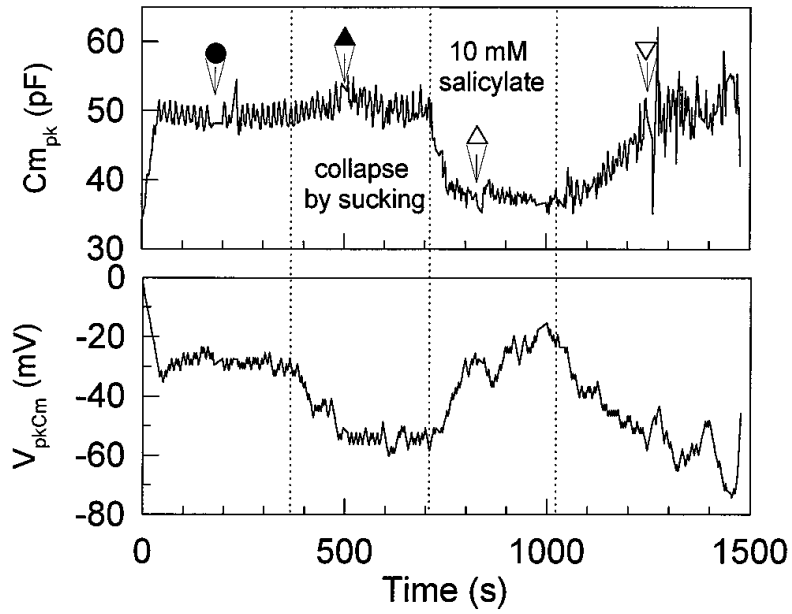

B

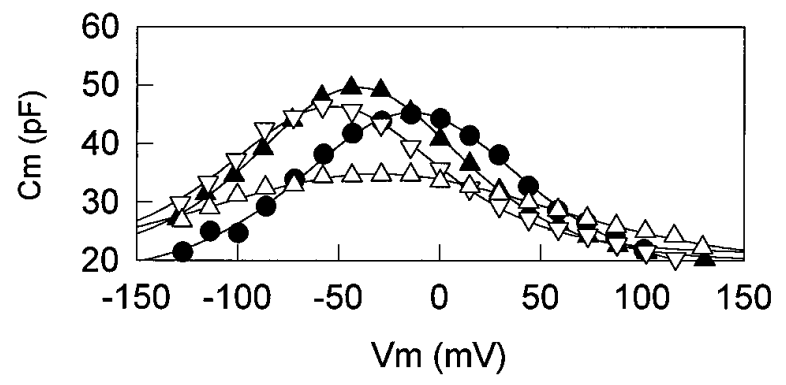

C

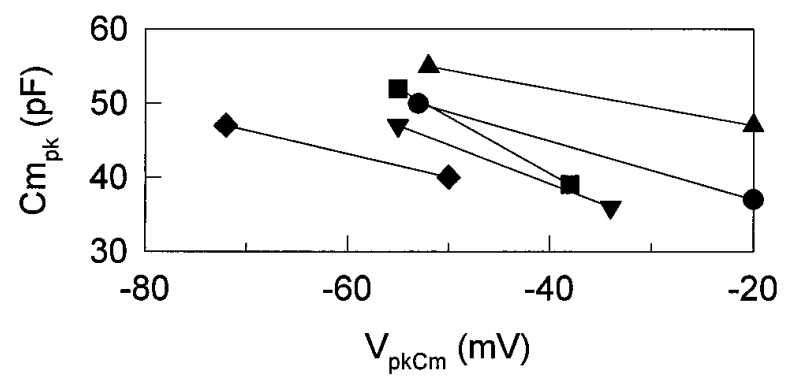

Figure 8. Effects of salicylate on the limited value of $V_{\mathrm{pkCm}}$. Intracellular pressure of the $\mathrm{OHC}$ was reduced directly through the patch pipette to collapse the cell. $A$, The cell was maintained in collapse after the point indicated by the first dotted line. As expected, collapsing the cell caused $C m_{\mathrm{pk}}$ to increase and $V_{\mathrm{pkCm}}$ to shift to a limiting negative value (Kakehata and Santos-Sacchi, 1995). At the second dotted line, $10 \mathrm{~mm}$ salicylate was applied extracellularly. $V_{\mathrm{pkCm}}$ shifted in the positive direction with a decrease in $C m_{\mathrm{pk}}$. Washout at the third dotted line caused recovery. $B$, Capacitance function determined by the stair-step protocol for the same cell. Fits (solid lines) to the capacitance data indicate $V_{\mathrm{pkCm}}, Q_{\mathrm{max}}$, and $z$ of $-14.3 \mathrm{mV}, 4.74 \mathrm{pC}$, and 0.650 (closed circles, control); $-41.0 \mathrm{mV}, 4.09$ $\mathrm{pC}$, and 0.743 (closed triangles, after collapse); $-32.3 \mathrm{mV}, 3.86 \mathrm{pC}$, and 0.418 (open triangles, during application of salicylate); $-53.6 \mathrm{mV}, 3.54 \mathrm{pC}$, and 0.728 (closed triangles, after wash). $C$, Data from five cells showing consistent positive shift of $V_{\mathrm{pkCm}}$ and decrease in $C m_{\mathrm{pk}}$ in collapsed cells after $10 \mathrm{~mm}$ salicylate treatment.

Intracellular pressure was reduced directly through the patch pipette. This treatment increased $C m_{\mathrm{pk}}$ and shifted $V_{\mathrm{pkCm}}$ in the negative direction. In this case, $V_{\mathrm{pkCm}}$ reached a limiting value of $-55 \mathrm{mV}$ when the $\mathrm{OHC}$ collapsed. After treatment with $10 \mathrm{~mm}$ salicylate extracellularly, the limiting value consistently moved in the positive direction while the OHC remained collapsed $(n=5)$. The effect was reversible. This result further suggests that salicylate does not act via turgor pressure but affects the voltage dependence of the voltage sensor directly. It also may indicate that the minority of cells in which salicylate shifted $V_{\mathrm{pkCm}}$ to negative potentials simultaneously may have experienced inadvertent changes in turgor pressure.

\section{Effects of salicylate on $\boldsymbol{V}_{\mathrm{pkCm}}$ and $\mathrm{Cm}_{\mathrm{pk}}$ of trypsin-treated cells}

It has been demonstrated that salicylate alters the structure of the OHC subsurface cisternae (Dieler et al., 1991). To investigate whether normal subsurface cisternae are required for the effects of salicylate on the voltage sensor, we disrupted subsurface cisternal architecture by destroying the cortical cytoskeleton of the cell with intracellular trypsin. This treatment causes the $\mathrm{OHC}$ to become spherical and the subsurface cisternae to vesiculate and peel away from the plasmalemma (Huang and Santos-Sacchi, 1994). Neither voltage-sensor gating charge movement nor the sensitivity of the sensor to intracellular pressure change is altered with this treatment (Kakehata and Santos-Sacchi, 1995). Figure 9 illustrates the persisting, reversible effects of salicylate on trypsintreated OHCs. After the cell became fully spherical at $\sim 13 \mathrm{~min}$, $10 \mathrm{~mm}$ salicylate was applied extracellularly. Detailed measures of voltage-dependent capacitance also were made by using stair-step stimuli before, during, and after application of salicylate. Salicylate consistently and reversibly reduced voltage-dependent capacitance $(n=3)$, suggesting that salicylate acts directly on the membrane-bound motor/sensor and not via the subsurface cisternae.

\section{DISCUSSION}

Previously, we demonstrated that intracellular pressure directly shifts the voltage dependence of membrane capacitance and motility in OHCs (Kakehata and Santos-Sacchi, 1995). Increasing pressure shifts $V_{\mathrm{pkCm}}$ and $V_{\delta \mathrm{Lmax}}$ to positive potentials while simultaneously suppressing $\mathrm{Cm}_{\mathrm{pk}}$; decreasing pressure has the opposite effects. In addition, even with iso-osmolar intra- and extracellular solutions, $V_{\mathrm{pkCm}}$ slowly moves to more hyperpolarized voltages after whole-cell configuration is established. This phenomenon is believed to underlie the variability of $V_{\mathrm{pkCm}}$ in isolated OHCs. Thus, in evaluating OHC voltage-dependent movement and membrane capacitance, the effects of intracellular pressure have to be taken into account. In the present study, we used techniques to minimize or control for the effects of intracellular pressure. Under such conditions, it is clear that salicylate and lanthanides exert their effects independent of turgor pressure.

Two other reports have investigated the effects of salicylate on motility or membrane capacitance by the use of whole-cell voltage clamp (Shehata et al., 1991; Tunstall et al., 1995). Neither controlled for pipette-mediated intracellular pressure changes, because large-tipped pipettes were used (2-5 M $\Omega, 1.5-3 \mu \mathrm{m})$. Reduction of electromotility because of loss of turgidity by extracellularly applied salicylate was reported (Shehata et al., 1991), and disruption of subsurface cisternae was thought to be related to this phenomenon (Dieler et al., 1991). However, our data do not support their conclusions. First, salicylate suppresses $C m_{\mathrm{pk}}$ and shifts $V_{\mathrm{pkCm}}$ to depolarized potentials-opposite the effects of decreasing turgor pressure. Second, extracellular salicylate application for up to $300 \mathrm{sec}$ induced an apparent collapse of only one OHC $(n=11)$ in whole-cell configuration with clamped, positive pressure. No unpatched, isolated cells showed any detectable collapse when $10 \mathrm{~mm}$ salicylate was applied extracellularly for $>10$ min, which is in accord with previous findings (Shehata et al., 1991). In addition, only 2 of 11 OHCs tested with internal $10 \mathrm{~mm}$ 

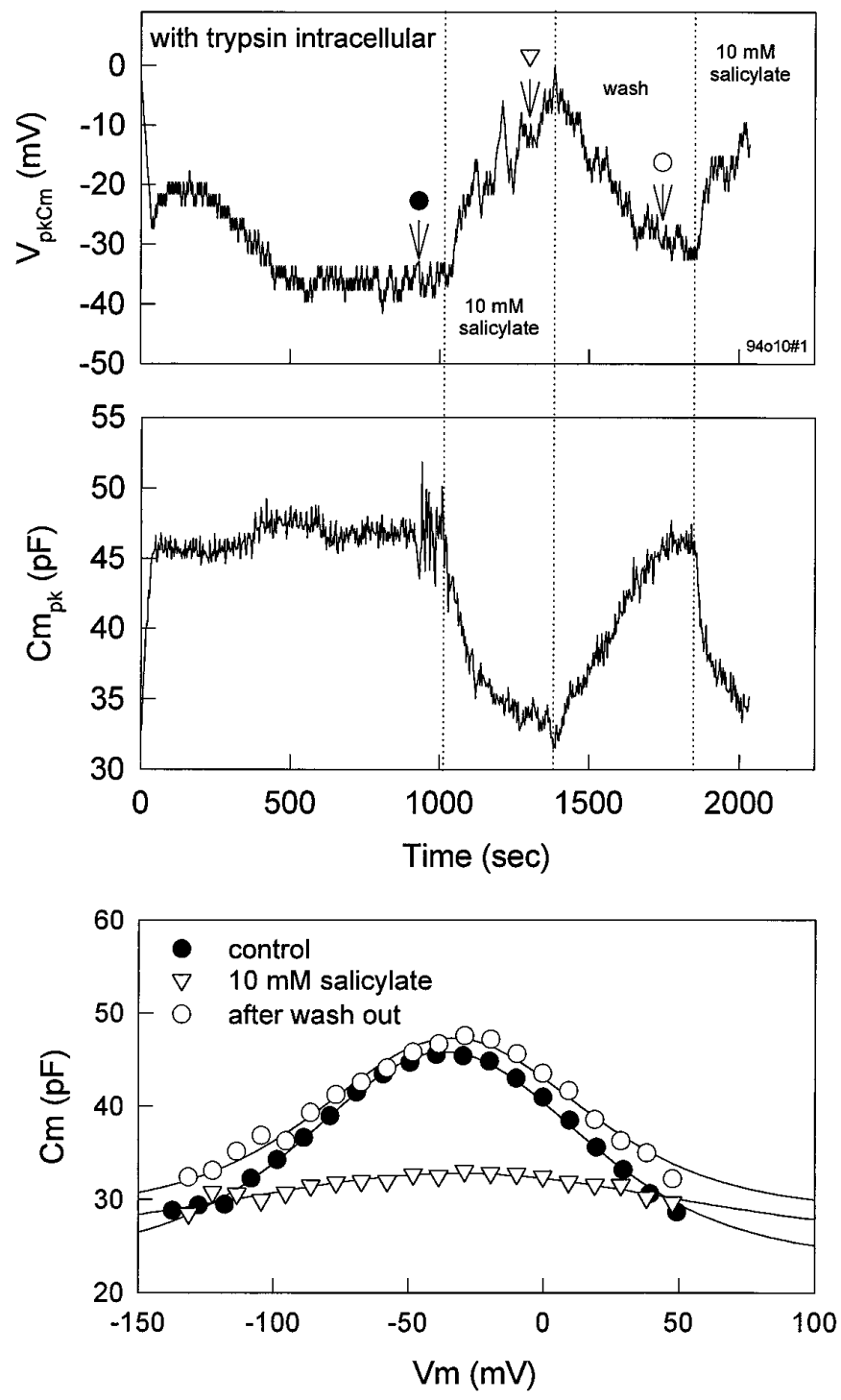

Figure 9. Effects of salicylate on $V_{\mathrm{pkCm}}$ and $C m_{\mathrm{pk}}$ of a trypsin-treated cell. Trypsin $(300 \mathrm{~g} / \mathrm{ml})$ was included in the patch pipette. After the cell became fully spherical at $\sim 13 \mathrm{~min}, 10 \mathrm{~mm}$ salicylate was applied extracellularly. Voltage-dependent capacitance was measured before, during, and after application of salicylate. Salicylate reduced voltage-dependent capacitance reversibly, despite permanent disruption of the subsurface cisternae. Fits (solid lines) for capacitance indicate $V_{\mathrm{pkCm}}, Q_{\max }$, and $z$ of $-36.6 \mathrm{mV}$, $3.04 \mathrm{pC}$, and 0.757 (closed circles); $-32.0 \mathrm{mV}, 1.69 \mathrm{pC}$, and 0.450 (open triangles). The fit to open triangles is unreliable because of the shallowness of the function.

salicylate collapsed after $3 \mathrm{~min}$. These time periods are far longer than necessary for the effects we observe on the sensor/motor. Third, in the OHCs treated with trypsin, in which the normal arrangement between membrane and subsurface cisternae is disrupted, effects of salicylate on the membrane voltage sensor remained. Thus, it is likely that the mechanisms of salicylate effects on the membrane sensor/motor and the subsurface cisternae are different and that the action of salicylate on the membrane sensor/motor is faster than that on the subsurface cisternae, which requires $>10 \mathrm{~min}$ for detectable effects (Dieler et al., 1991).

Tunstall et al. (1995) reported values of the Hill coefficient $(n)$ and half-maximal concentration $\left(K_{1 / 2}\right)$ for salicylate of 3.40 and
$3.95 \mathrm{~mm}$, respectively. From these data they deduced that the sensor/motor within the $\mathrm{OHC}$ membrane is a tetramer, as originally suggested by Kalinec et al. (1992). Our results indicate an $n$ of 1.0 and $K_{1 / 2}$ of $1.6 \mathrm{~mm}$. These apparent differences can be accounted for. Tunstall et al. obtained their dose-response curve at a fixed voltage of $-50 \mathrm{mV}$, but they did not attempt to keep intracellular pressure constant. Measured capacitance at a fixed voltage may be subject to fluctuation induced by inadvertent turgor pressure change. Nevertheless, one cell was evaluated at four different membrane potentials with similar results, and data collection was rapid, indicating that pressure changes in their cells may not have been significantly influential. More importantly, however, their dose-response curves were obtained with a perfusion technique (monitoring the drug concentration increase near the cell after the start of a continuous flow of $10 \mathrm{~mm}$ salicylate), which presented salicylate for too short a period of time at low concentrations to allow $\mathrm{Cm}$ levels to reach steady state. As we demonstrated in this paper, tau of salicylate-induced reduction in $C m_{\mathrm{pk}}$ was $19.2 \pm 3.7$ and $11.4 \pm 2.4 \mathrm{sec}$ for 1 and $10 \mathrm{~mm}$ salicylate, respectively (see also Fig. 5 in Tunstall et al., 1995; tau of $5 \mathrm{~mm}$ salicylate-induced reduction in $\mathrm{Cm}$ is $\sim 15 \mathrm{sec}$ ). Their Figure 8 indicates that exposure time at each measured concentration below $10 \mathrm{~mm}$ was no more than a few seconds, total perfusion time from 0 to $10 \mathrm{~mm}$ being $30 \mathrm{sec}$. Such short application times would make their dose-response curve steeper and $K_{1 / 2}$ larger than actual and also would account for the nonsymmetrical shape of their data.

In the present experiments, we obtained the concentrationresponse curve by measuring changes in the maximum capacitance of the cell $\left(\mathrm{Cm}_{\mathrm{pk}}\right)$, and various concentrations of salicylate were applied for at least $120 \mathrm{sec}$, allowing steady levels to be reached. In addition, we attempted to control for the effects of inadvertent intracellular pressure change. Although the $K_{1 / 2}$ we observed was $1.6 \mathrm{~mm}$, effects on the sensor/motor were observed in the hundred micromolar range. It has been shown that the perilymphatic salicylate concentration, which induces tinnitus and hearing loss in the rat, is near $400 \mu \mathrm{M}$ (Jastreboff et al., 1986). Therefore, the data we obtain in vitro are in accord with in vivo results. The value of the Hill coefficient for salicylate obtained in this experiment is 1.0 , which indicates that there is one binding site per sensor/motor molecule for salicylate. This type of information is not sufficient to speculate on the number of sensor/motor subunits but simply points to a lack of cooperativity.

Our data permit us to speculate on the site and mechanism of salicylate action. Salicylic acid, transported in the undissociated or unionized form, is highly permeable across lipid bilayers (Gutknecht and Tosteson, 1973) and human red cell membranes (Joy and Cutler, 1987). When salicylic acid enters a cell, dissociation to salicylate occurs, with the final concentration of the dissociated form being dependent on intracellular $\mathrm{pH}(\mathrm{pHi})$. Because $\mathrm{pHi}$ decreases on application of extracellular salicylate under wholecell recording conditions (Tunstall et al., 1995), the resulting level of intracellular salicylate at equilibrium is less than that of extracellular salicylate. Given the pKa of salicylic acid (3.0), it can be calculated from the Henderson-Hasselbalch equation that $0.6 \mu \mathrm{M}$ salicylic acid will exist as the undissociated form at a $10 \mathrm{~mm}$ extracellular concentration of salicylate anion. Assuming that extracellularly applied $10 \mathrm{~mm}$ salicylate causes pHi to shift from 7.2 to 6.9 , then the concentration of salicylate inside the cell would be $5 \mathrm{~mm}$ at equilibrium. The actual pHi change would depend on the efficacy of the patch solution buffer. The relatively slow time 
course of salicylate action by extracellular perfusion may correspond to the time taken for salicylate to form intracellularly. In fact, Tunstall et al. (1995) showed that pHi changed from 7.2 to 6.9 in $30 \mathrm{sec}$. This time course should reflect directly the dissociation of $\mathrm{H}^{+}$from salicylic acid. Because they also showed that $\mathrm{pHi}$ itself is not the main cause of capacitance decrease, we conclude that the change in capacitance that we note with extracellular salicylate is attributable to the production of the dissociated form. On the other hand, when $10 \mathrm{~mm}$ sodium salicylate solution buffered to $\mathrm{pH} 7.2$ is introduced intracellularly, the effect is almost immediate and more pronounced, presumably because the dissociated form is delivered directly and at higher concentrations. It should be emphasized that, for either intracellular or extracellular application, the concentration of salicylic acid would be the same $(0.6 \mu \mathrm{M})$. That is, the residence of the uncharged form within the membrane probably does not interfere with the sensor/motor. Thus, our data, which demonstrate that salicylate acts faster and to a greater extent when dialyzed into the $\mathrm{OHC}$, suggest that salicylate works on the sensor/motor in the dissociated, charged form. The ability of the dissociated, charged form of salicylate to interact with the sensor/motor on the inner aspect of the plasma membrane may underlie the voltage dependence shifts that we observe in the capacitance functions. Although salicylate is effective on the intracellular aspect of the lateral plasma membrane, we show that lanthanides function exclusively on the outer aspect. These results are contrary to those reported by Gale and Ashmore (1994a).

The comparison between mechanical movements and charge movements in treated cells indicates that, whereas charge movement is suppressed to nearly the same extent by salicylate and lanthanides, motility is not. Mechanical responses remain substantial after salicylate treatment, but the motility function becomes linear between the range of -150 and $+150 \mathrm{mV}$. It should be noted, however, that in both cases residual nonlinear capacitance remains. The difference between mechanical responses obtained with the two treatments may relate to differential changes in the axial stiffness of the cell under each condition. It has been found that extracellularly applied salicylate reversibly reduces axial stiffness of isolated $\mathrm{OHCs}$ of guinea pig (Russell et al., 1995), which may be related to the demonstration of a reversible decrease in OHC lateral wall stiffness (Lue et al., 1996). Under such conditions, the residual charge movement may correspond to conformational changes of the motor molecule that are capable of driving an unloaded cell with reduced axial stiffness. Lanthanide treatment, on the other hand, may increase axial stiffness. This may be indicated by the elongation and apparent stiffening of the OHC noted with lanthanide treatments (Santos-Sacchi, 1991; Kakehata and Santos-Sacchi, 1995). Under conditions of increased axial stiffness, the conformation change of the motor, indicated by the residual charge movement, may be unable to effect mechanical responses.

In conclusion, we show that salicylate and lanthanides do not work via mechanisms similar to changes in intracellular turgor pressure. The effects seem to be a result of direct action on the motility sensor/motor: lanthanides working on the external aspect of the lateral membrane and salicylates working on the intracellular aspect. It is interesting to note that simple modifications to the salicylate molecule, which would limit its entry into the $\mathrm{OHC}$, are predicted to eliminate the attendant tinnitus and hearing loss associated with the ingestion of the drug.

\section{REFERENCES}

Ashmore JF (1987) A fast motile response in guinea-pig outer hair cells: the cellular basis of the cochlear amplifier. J Physiol (Lond) 388:323-347.

Ashmore JF (1989) Transducer motor coupling in cochlear outer hair cells. In: Mechanics of hearing (Kemp D, Wilson JP, eds), pp 107-113. New York: Plenum.

Ashmore JF (1992) Mammalian hearing and the cellular mechanism of the cochlear amplifier. In: Sensory transduction (Corey DP, Roper SD, eds), pp 395-412. New York: Rockefeller UP.

Brownell WE, Bader CR, Bertrand D, de Ribaupierre Y (1985) Evoked mechanical responses of isolated cochlear outer hair cells. Science 227:194-196.

Carlyon RP, Butt M (1993) Effects of aspirin on human auditory filters. Hear Res 66:233-244.

Dallos P (1992) The active cochlea. J Neurosci 12:4575-4585.

Dallos P, Evans BN, Hallworth R (1991) Nature of the motor element in electrokinetic shape changes of cochlear outer hair cells. Nature 350:155-157.

Dieler R, Shehata WE, Dieler W, Brownell WE (1991) Concomitant salicylate-induced alterations of outer hair cell subsurface cisternae and electromotility. J Neurocytol 20:637-653.

Gale JE, Ashmore JF (1994a) An intracellular site for the inhibition of outer hair cell motility by gadolinium? Soc Neurosci Abstr 1:1.

Gale JE, Ashmore JF (1994b) Charge displacement induced by rapid stretch in the basolateral membrane of the guinea-pig outer hair cell. Proc R Soc Lond [Biol] 255:243-249.

Gutknecht J, Tosteson DC (1973) Diffusion of weak acids through lipid bilayer membranes: effect of chemical reactions in the aqueous unstirred layer. Science 182:1258-1261.

Hamill OP, Marty A, Neher E, Sakmann B, Sigworth FR (1981) Improved patch-clamp techniques for high-resolution currents recording from cells and cell-free membrane patches. Pflügers Arch 391:85-100.

Huang G-J, Santos-Sacchi J (1993) Mapping the distribution of the outer hair cell motility voltage sensor by electrical amputation. Biophys $\mathbf{J}$ 65:2228-2236.

Huang G-J, Santos-Sacchi J (1994) Motility voltage sensor of the outer hair cell resides within the lateral plasma membrane. Proc Natl Acad Sci USA 91:12268-12272.

Iwasa KH (1993) Effect of stress on the membrane capacitance of the auditory outer hair cell. Biophys J 65:492-498.

Iwasa KH (1994) A membrane motor model for the fast motility of the outer hair cell. J Acoust Soc Am 96:2216-2224.

Jastreboff PJ, Hansen R, Sasaki PG, Sasaki CT (1986) Differential uptake of salicylate in serum, cerebrospinal fluid, and perilymph. Arch Otolaryngol Head Neck Surg 112:1050-1053.

Joy MM, Cutler DJ (1987) On the mechanism of transport of salicylate and p-hydroxybenzoic acid across human red cell membrane. J Pharm Pharmacol 39:266-271.

Kakehata S, Santos-Sacchi J (1995) Membrane tension directly shifts voltage dependence of outer hair cell motility and associated gating charge. Biophys J 68:2190-2197.

Kakehata S, Nakagawa T, Takasaka T, Akaike N (1993) Cellular mechanism of acetylcholine-induced response in dissociated outer hair cells of guinea-pig cochlea. J Physiol (Lond) 463:227-244.

Kalinec F, Holley MC, Iwasa KH, Lim DJ, Kachar B (1992) A membrane-based force generation mechanism in auditory sensory cells. Proc Natl Acad Sci USA 89:8671-8675.

Kujawa SG, Fallon M, Bobbin RP (1992) Intracochlear salicylate reduces low-intensity acoustic and cochlear microphonic distortion products. Hear Res 64:73-80.

Long GR, Tubis A (1988) Modification of spontaneous and evoked otoacoustic emissions and associated psychoacoustic microstructure by aspirin consumption. J Acoust Soc Am 84:1343-1353.

Lue AJ-C, Weng TX, Spector AA, Popel AS, Brownell WE (1996) Salicylate-induced changes of outer hair cell lateral wall stiffness. Soc Neurosci Abstr 2:2.

McFadden D, Plattsmier HS (1984) Aspirin abolishes spontaneous otoacoustic emissions. J Acoust Soc Am 76:443-448.

Mongan E, Kelly P, Nies K, Porter WW, Paulus HE (1973) Tinnitus as an indication of therapeutic serum salicylate levels. JAMA 226:142-145. 
Murase K, Randic M, Shirasaki T, Nakagawa T, Akaike N (1990) Serotonin suppresses $N$-methyl-D-aspartate responses in acutely isolated rat spinal dorsal horn neurons. Brain Res 525:84-91.

Myers EN, Bernstein JM (1965) Salicylate ototoxicity: a clinical and experimental study. Arch Otolaryngol Head Neck Surg 82:483-493.

Puel JL, Bledsoe SJ, Bobbin RP, Ceasar G, Fallon M (1989) Comparative actions of salicylate on the amphibian lateral line and guinea pig cochlea. Comp Biochem Physiol 93:73-80.

Russell IJ, Murugasu E, Schauz C (1995) The effects of salicylate on the mechanics of the basilar membrane and isolated outer hair cells of the guinea pig cochlea. Soc Neurosci Abstr 3:3.

Santos-Sacchi J (1989) Asymmetry in voltage-dependent movements of isolated outer hair cells from the organ of Corti. J Neurosci 9:2954-2962.

Santos-Sacchi J (1991) Reversible inhibition of voltage-dependent outer hair cell motility and capacitance. J Neurosci 11:3096-3110.
Santos-Sacchi J (1993) Harmonics of outer hair cell motility. Biophys J 65:2217-2227.

Santos-Sacchi J, Dilger JP (1988) Whole-cell currents and mechanical responses of isolated outer hair cells. Hear Res 35:143-150.

Shehata WE, Brownell WE, Dieler R (1991) Effects of salicylate on shape, electromotility, and membrane characteristics of isolated outer hair cells from guinea pig cochlea. Acta Otolaryngol (Stockh) 111:707-718.

Tunstall MJ, Gale LE, Ashmore JF (1995) Action of salicylate on membrane capacitance of outer hair cells from the guinea-pig cochlea. J Physiol (Lond) 485:739-752.

Zhi M, Phillips B, Brownell WE (1996) Alkaline cytoplasm and $\mathrm{pH}$ gradients in outer hair cell: evidence for a proton pump. Soc Neurosci Abstr 4:4. 